\title{
In silico Analysis and Molecular Modelling of NADH-cytochrome b5 Reductase 3 involved in Methemoglobinemia
}

\author{
Someshwar C. M. Moholkar*, Mamta S. Kongari, Shubhangi S. Sakhare
}

P.G. Research Center in Bioinformatics, Walchand Center for Biotechnology, Walchand college of Arts and Science, Solapur, Maharashtra, India

\begin{abstract}
Methemoglobinemia is type of disease caused due to methemoglobin. Methemoglobin is type of hemoglobin in which the iron heme ${ }^{3+}$ is present instead of $\mathrm{fe}^{2+}$. Normally methemoglobin is present in every living cell, but if it is present in large amount then it will responsible for causing disease. Acquired methemoglobinemia known as acute methemoglobinemia caused by exposure of medicines, chemicals, foods. People suffering from genetic form have higher chances of developing acquired type. Most cases of acquired methemoglobinemia result from exposure to certain drugs or toxins. In the present study we have used different Insilico tools and techniques which are includes retrieval of NADH-cytochrome b5 reductase 3protein sequence from the UniProt KB database and physicochemical parameter analyzed by using Protoparam tool. In that Leucine had a maximum amino acid composition. The structure of a protein has a very important role in its function. The secondary structure was predicted by using SOPMA tool which indicated that the percentage of Random coils was higher than the percentage of alpha helix and extended strand. Then the 3D structure of b5 reductase 3 was predicted by using SWISS MODEL server and the model was validated by using PROCHECK analysis after validation of the model, the validation score was $94.7 \%$.
\end{abstract}

Keywords : Methemoglobinemia, Insilico, reductase, Nitrate, Random Coil, secondary structure.

\section{INTRODUCTION}

Methemoglobin lacks the electron that is needed to form a bond with oxygen and thus is incapable of oxygen transport. The low level of methemoglobin is maintained through 2 important mechanisms. The first is the hexose-monophosphate shunt pathway within the erythrocyte. Through this pathway, oxidizing agents are reduced by glutathione. The second and more important mechanism involves 2 enzyme systems, diaphorase I and diaphorase II, and requires nicotinamide adenine dinucleotide (NADH) and nicotinamide adenine dinucleotide phosphate $(\mathrm{NADPH})$, respectively, to reduce methemoglobin to its original ferrous state. Any drug that interferes with these mechanisms can lead to Methemoglobinemia [1]. Acquired Methemoglobinemia incidence may be much higher than is documented. Often, this is associated with the use of or exposure to oxidant drugs, chemicals, or toxins, including dapsone, local anesthetic agents, and nitroglycerin [2]. On the other hand, evaluating all the signs and symptoms together with laboratory results is important in diagnosis of rare diseases such as methemoglobinemia. The disease is caused by mutations affecting the gene represented in this entry. Disease description a form of methemoglobinemia, a hematologic disease characterized by the presence of 
excessive amounts of methemoglobin in blood cells, resulting in decreased oxygen carrying capacity of the blood, cyanosis and hypoxia. There are two types of methemoglobinemia CYB5R3-related. In type 1, the defect affects the soluble form of the enzyme, is restricted to red blood cells, and causes well-tolerated methemoglobinemia. In type 2 , the defect affects both the soluble and microsomal forms of the enzyme and is thus generalized, affecting red cells, leukocytes and all body tissues. Type 2 methemoglobinemia is associated with mental deficiency and other neurologic symptoms. The enzymatic type of methemoglobinemia has unprecedentedly high frequency in the Athabaskan Indians (Eskimos) of Alaska observed CYB5R3 deficiency in Navajo Indians. Since the Navajo Indians and the Athabaskan Indians of Alaska are the same linguistic stock, the finding may illustrate the usefulness of rare recessive genes in tracing relationships of ethnic groups [4]. Methemoglobinemia, although not usually considered an inborn error of metabolism in the strict garrodian sense, was the first hereditary trait in which a specific enzyme deficiency was identified [5]. Methemoglobinemia is a life-threatening condition whose symptoms worsen as the MetHb level increases, with a high occurrence of mortality being observed at MetHb levels above 70\% [6]. The first step includes retrieval of $\mathrm{NADH}$-cytochrome b5 reductase 3 protein sequence from UniProtKB database. The physiochemical properties were analyzed by using ProtParam tool and the secondary structure was predicted by using SOPMA secondary structure prediction tool. Later the 3D structure was predicted by using SWISS-MODEL server and the model was validated by using PROCHECK method.

\section{MATERIAL AND METHODS}

\section{Retrieval of Protein Sequence}

The protein sequence of NADH-cytochrome b5 reductase 3 proteins was retrieved from UniProtKB protein database and saved in FASTA file format. UniProtKB is a protein sequence database which is freely accessible to the public and it contains the amino acid sequences of proteins [7].

\section{Physicochemical properties analysis}

The physicochemical properties of NADHcytochrome b5 reductase 3 proteins were analyzed by ProtParam analysis tool. The ProtParam tool calculates parameters such as amino acid composition, molecular weight theoretical pI, instability index, aliphatic index and grand average of hydropathicity (GRAVY) [8].

\section{Secondary Structure prediction and analysis}

The secondary structure was predicted by SOPMA (Self- Optimized Prediction Method with Alignment) method. It was employed for calculating the secondary structural of NADH-cytochrome b5 reductase 3 proteins. The SOPMA method correctly predicts the secondary structure $\alpha$-helix, $\beta$-sheet and coil [9].

\section{Homology Modeling and Model Validation The of} $\mathrm{NADH}$-cytochrome b5 reductase 3 sequence was used for comparative homology modeling using SWISS MODEL server. SWISS-MODEL is a fully automated protein structure homology modeling server to make the protein models accessible to all biotechnologist [10]. After modeling, to check the quality and validation of the model was carried out by PROCHECK Ramchandran plot method using PDBsum server [11]. 


\section{Identification of Domain function and analysis}

Identification of domain and its biological function of $\mathrm{NADH}$-cytochrome b5 reductase 3 proteins were determined from Pfam domain identification database. The Pfam database is a large collection of protein families, each represented by multiple sequence alignments and hidden Markov models (HMMs) [12]

\section{RESULTS AND DISCUSSION}

\section{Retrieval of NADH-cytochrome b5 reductase 3 protein}

The protein sequence of $\mathrm{NADH}$-cytochrome b5 reductase 3 proteins was retrieved from UniProt $\mathrm{KB}$ database and the sequence was saved in FASTA file format in notepad. The protein name, organism name, UniProt KB ID and sequence length were shown in table 1.

Table.1 Retrieval of sequence

\begin{tabular}{|c|c|c|c|}
\hline $\begin{array}{c}\text { Protein } \\
\text { Name }\end{array}$ & $\begin{array}{c}\text { Organism } \\
\text { Name }\end{array}$ & UniprotKB Id & $\begin{array}{c}\text { Sequence } \\
\text { length }\end{array}$ \\
\hline $\begin{array}{c}\text { NADH- } \\
\text { cytochrome } \\
\text { b5 } \\
\text { reductase 3 }\end{array}$ & $\begin{array}{c}\text { Homo } \\
\text { sapiens }\end{array}$ & P00387 & 301 \\
\hline
\end{tabular}

\section{Physicochemical analysis of Protein}

The physicochemical properties were analyzed by using ProtParam tool and the results were enlisted in table 2. As per the table, the NADH-cytochrome b5 reductase 3 is unstable and basic in nature. The total number of positively charged residues (Arg+Lys) and negatively charged residues (Asp+Glu) are same in number as shown in Table. 2 .
Table. 2. Physicochemical parameters of NADHcytochrome b5 reductase 3

\begin{tabular}{|l|l|}
\hline Parameters & Values \\
\hline Total No. of Amino acids & 301 \\
\hline Molecular weight & 34234.86 \\
\hline Theoretical pI & 7.18 \\
\hline UniprotKB ID & P00387 \\
\hline $\begin{array}{l}\text { The number of positive amino acids } \\
\text { (Arg+Lys) }\end{array}$ & 34 \\
\hline $\begin{array}{l}\text { The number of negative amino } \\
\text { acids (Asp+Glu) }\end{array}$ & 34 \\
\hline Extinction coefficient & 0.917 \\
\hline Aliphatic index & 91.96 \\
\hline GRAVY & -0.190 \\
\hline
\end{tabular}

\section{Secondary Structure Prediction}

The secondary structure was predicted by using SOPMA method. The secondary structure elements like alpha helix, beta sheets, extended strand and random coils were enlisted in Table 3 . From the table, the percentage of coils in NADH-cytochrome b5 reductase 3 proteins was higher than the percentage of alpha helix and extended strand.

Table. 3 Secondary Structure Prediction

\begin{tabular}{|l|l|l|}
\hline $\begin{array}{l}\text { Secondary } \\
\text { Structure } \\
\text { Elements }\end{array}$ & $\begin{array}{l}\text { Number of } \\
\text { residues }\end{array}$ & Percentage \\
\hline Alpha helix & 73 & $24.25 \%$ \\
\hline $\begin{array}{l}\text { Extended } \\
\text { Strand }\end{array}$ & 75 & $24.92 \%$ \\
\hline Beta turn & 21 & $6.98 \%$ \\
\hline Random coil & 132 & $43.85 \%$ \\
\hline
\end{tabular}




\section{Homology Modeling and Model Validation}

The 3D structure of NADH-cytochrome b5 reductase 3 proteins was predicted by the SWISS Model server. The sequence template NADH-cytochrome b5 reductase 3 proteins were selected as template for prediction of homology modelling. The quality and validation of the model was carried out by Ramchandran plot analysis using PDBsum server. Ramchandran plot analysis showed that the percentage of favored region is $94.7 \%$ which was higher than the percentage of additional allowed region it's conclude that the predicted model was reliable and good quality shown in Fig.1. Further model was visualized in RasMol visualization software package as shown in figure2.

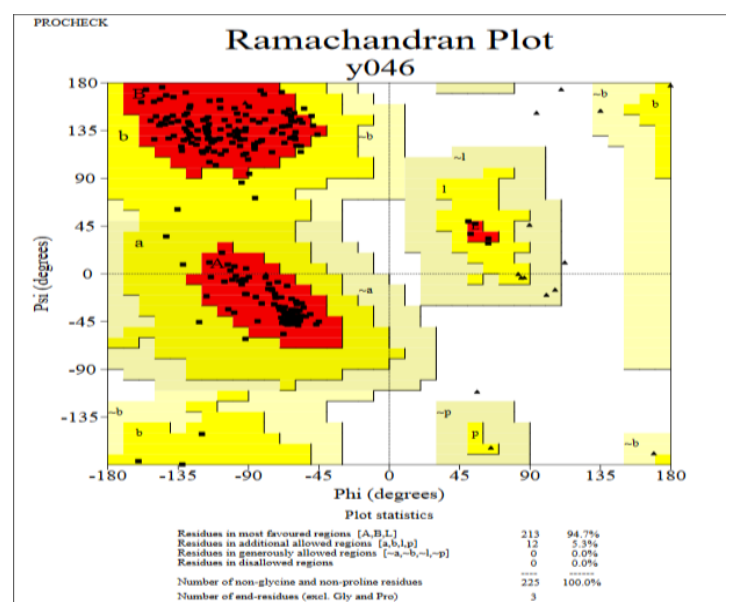

Fig.1 Protein model validation by PROCHECK

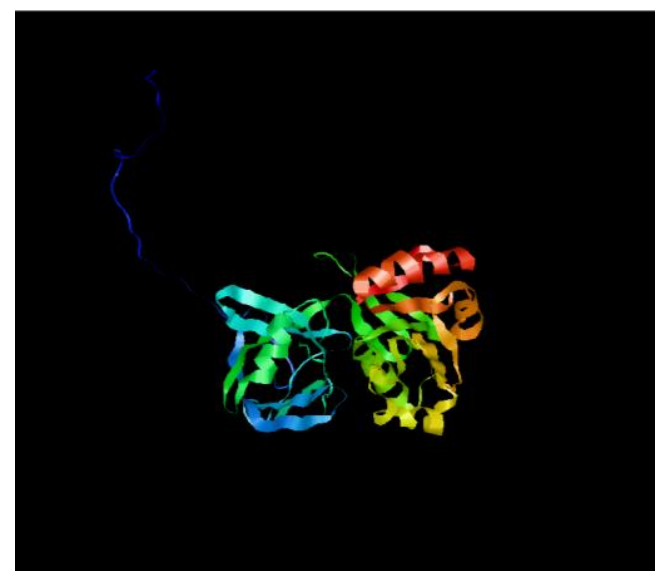

Fig.2. Visulatization of Predicted 3D structure by RasMol

\section{Identification of Domain function and analysis}

The Protein domain and protein family analysis of $\mathrm{NADH}$-cytochrome b5 reductase 3 proteins by Pfam database. The domain of NADH-cytochrome b5 reductase 3 proteins and its sequence length was shown in Fig. 3.

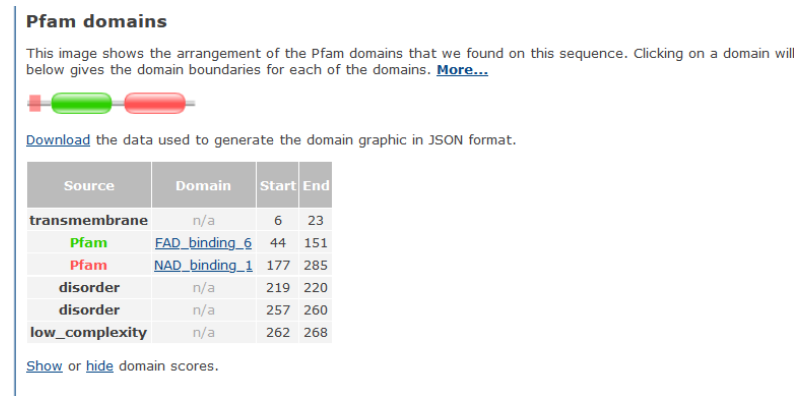

Fig. 3. Domain identification with its sequence length

\section{CONCLUSIONS}

The present preliminary investigation mainly leads to understand the basic primary, secondary structure and tertiary structure of NADH-cytochrome b5 reductase 3 proteins In-silico tools and techniques. The NADH-cytochrome b5 reductase 3 proteins were retrieved from UniprotKB database and it is having length of 301. The primary protein sequence analysis carried out using protparam tool and it retrieval that having a Molecular weight - 34234.86 Da, Theoretical pI - 7.18, The number of positive amino acids (Arg + Lys): 34 , The number of negative amino acids (Asp + Glu): 34 respectively. Aliphatic index: 91.96, GRAVY: -0.180. Secondary structure of the NADHcytochrome b5 reductase 3 proteins was predicted by SOMPA having alpha helix-73, beta turns 21, extended strands 42 ; random coils 87 so protein was highly stable. The Modelling of 3D structure of $\mathrm{NADH}$-cytochrome b5 reductase 3 proteins was build by Swiss model 2xfc. Structure was validated using PROCHECK having model quality was $94.7 \%$. This present study put molecular insight into the further studies to find the structural and functional properties 
of these NADH-cytochrome b5 reductase 3 proteins to find or design the novel antiviral drugs of Chikungunya virus by Structure based drug design approach.

\section{REFERENCES}

[1]. Herman M.I., Chyka P.A., Butler A.Y., Rieger S.E. Methylene blue by intraosseous infusion for methemoglobinemia. Ann Emerg Med. 1999; 33:111-113.

[2]. Wright R.O., Lewander W.J., Woolf A.D. Methemoglobinemia: etiology pharmacology, and clinical management. Ann Emerg Med. 1999;34:646-656.

[3]. Skold Anna, Dominique L., Cosco M.D., Robin Klein M.D. Methemoglobinemia: pathogenesis, diagnosis, and management. South Med J. November 2011; 104(11):757-761.

[4]. Scott, E. M. The relationship of diaphorase of human erythrocytes to inheritance of methemoglobinemia. J. Clin. Invest. 39: 11761179, 1960.5Gibson, Q. Introduction: congenital methemoglobinemia revisited. (Letter) Blood 100: 3445-3446, 2002.

[5]. S. Haymond, R. Cariappa, C.S. Eby and M.G. Scott, "Laboratory assessment of oxygenation in methemoglobinemia", Clin. Chem. 51(2), 434444 (2005).

[6]. Magrane M. And the UniProt consortium. UniProt Knowledgebase: a hub of integrated protein data Database, 2011, bar009.

[7]. Gasteiger, E., Gattiker, A., Hoogland, C., Ivanyi, I., Appel, R. D. and Bairoch, A. (2003).ExPASy - the proteomics server for indepth protein knowledge and analysis. Nucleic Acids Res. 31, 3784-3788.

[8]. MO Dayhoff. Fed Proc. 1976; 35(10):2132.

[9]. Arnold K, Bordoli L, Kopp J, Schwede T. The SWISSMODEL Workspace: A web-based environment for protein structure homology modelling. Bioinformatics 2006; 22:195-201

[10]. Laskowski RA, MacArthur MW, Moss DS, Thornton JM. PROCHECK - a program to check the stereochemical quality of protein structures. J App. Cryst. 1993; 26:283-29

[11]. Bateman,A., Birney,E., Durbin,R., Eddy,S.R. , Howe,K.L. and Sonnhammer,E.L.L. ( 200 The Pfam protein families databas Nucleic Acids Res., 28, 263-266.

\section{Cite this article as :}

Someshwar C. M. Moholkar, Mamta S. Kongari, Shubhangi S. Sakhare, "In silico Analysis and Molecular Modelling of NADH-cytochrome b5 Reductase 3 involved in Methemoglobinemia", International Journal of Scientific Research in Science and Technology (IJSRST), Online ISSN : 2395-602X, Print ISSN : 2395-6011, Volume 7 Issue 1, pp. 229-233, January-February 2020.

Journal URL : http://ijsrst.com/IJSRST207149 